\title{
Diagnosis of late-onset Pompe disease and other muscle disorders by next-generation sequencing
}

Sébastien Lévesque ${ }^{1 *}$, Christiane Auray-Blais ${ }^{1}$, Elaine Gravel1, Michel Boutin ${ }^{1}$, Laura Dempsey-Nunez ${ }^{1}$, Pierre-Etienne Jacques ${ }^{2}$, Sébastien Chenier ${ }^{1}$, Sandrine Larue ${ }^{3}$, Marie-France Rioux ${ }^{4}$, Walla Al-Hertani ${ }^{5}$, Amelie Nadeau ${ }^{6}$, Jean Mathieu ${ }^{7}$, Bruno Maranda ${ }^{1}$, Valérie Désilets ${ }^{1}$, Paula J. Waters ${ }^{1}$, Joan Keutzer ${ }^{8}$, Stephanie Austin ${ }^{9}$ and Priya Kishnani ${ }^{9}$

\begin{abstract}
Background: Late-onset Pompe disease (LOPD) is a rare treatable lysosomal storage disorder characterized by progressive lysosomal glycogen accumulation and muscle weakness, with often a limb-girdle pattern. Despite published guidelines, testing for LOPD is often overlooked or delayed in adults, owing to its low frequency compared to other muscle disorders with similar muscle patterns. Next-generation sequencing has the capability to test concurrently for several muscle disorders. This could potentially lead to increased diagnosis of LOPD, disorders with non-specific muscle weakness or atypical patients.

Methods: We developed a gene panel to further study its clinical utility in a cohort of patients with suspected muscle disorders. We designed a gene panel to analyze the coding sequences and splice site junctions of GAA causing LOPD, along with 77 other genes causing muscle disorders with overlapping phenotypes.

Results: At a median coverage of $\sim 200 X$ (sequences per base), all GAA exons were successfully covered with $>20 X$ and only $0.3 \%$ of exons across all genes were $<20 \mathrm{X}$. The panel showed an excellent sensitivity (100 \%) and specificity (98\%) across all selected genes, using known variations in Pompe patients and controls. We determined its clinical utility by analyzing 34 patients with suspected muscle disorders of undetermined etiology and various muscle patterns, who were referred or followed in neuromuscular and genetics clinics. A putative diagnosis was found in up to $32 \%$ of patients. The gene panel was instrumental in reaching a diagnosis in atypical patients, including one LOPD case. Acid alpha-glucosidase activity was used to confirm the molecular results in all patients.
\end{abstract}

Conclusion: This work highlights the high clinical utility of gene panels in patients with suspected muscle disorders and its potential to facilitate the diagnosis of patients showing non-specific muscle weakness or atypical phenotypes. We propose that gene panels should be used as a first-tier test in patients with suspected muscle disorders of undetermined etiology, which could further increase overall diagnosis of muscle conditions, and potentially reduce diagnostic delay. Further studies are necessary to determine the impact of first-tier gene panels on diagnostic delay and on treatment outcome for LOPD.

Keywords: Pompe disease, Lysosomal disorders, Muscle disorders, Next-generation sequencing

\footnotetext{
* Correspondence: Sebastien.A.Levesque@USherbrooke.ca

'Department of Pediatrics, Division of Medical Genetics, Faculty of Medicine

and Health Sciences, Université de Sherbrooke, and Centre Hospitalier

Universitaire de Sherbrooke, 3001, 12th Avenue North, Sherbrooke, QC J1H

$5 \mathrm{~N} 4$, Canada

Full list of author information is available at the end of the article
} 


\section{Background}

Pompe disease (OMIM 232300) is an autosomal recessive condition caused by mutation in the GAA gene, leading to a deficiency in acid alpha-glucosidase (OMIM 606800, EC 3.2.1.20) and accumulation of glycogen in all tissues, most notably in muscles and heart $[1,2]$. Pompe disease consists of a phenotypic continuum, however two broad categories are recognised: classic infantile and late onset forms $[3,4]$. Classical infantile Pompe disease presents in the first few months of life with hypertrophic cardiomyopathy, generalized muscle weakness, and respiratory distress [5]. Without enzyme replacement therapy (ERT), the disease is fatal within the first year of life in the vast majority of infantile cases [6]. Late-onset Pompe disease (LOPD) may present at any age from late infancy onwards, but most frequently develops during adulthood, either with motor delays or limb-girdle muscle weakness [7]. Some patients present with rigid spine syndrome, scoliosis and low body mass [7]. Diaphragmatic weakness is present in the vast majority of patients and leads to nocturnal hypoventilation. Presymptomatic patients can be identified by persistent, chronic elevation of serum creatine kinase, and a recent study showed a frequency of Pompe disease in $2.5 \%$ of patients with chronic hyperCKemia [8]. The combined incidence of all forms of Pompe disease at birth is estimated to be $1: 40,000$ in the US and similarly in Netherlands, with the adult onset form being 1:57,000 $[9,10]$. However, recent data from newborn screening program of Missouri state, Austria and Taiwan suggest that incidence is higher with respectively $1: 5463,1: 8684$ and $1: 11,987$ [11-13]. LOPD is likely underdiagnosed in neuromuscular clinics owing to the rarity of the condition and its marked phenotypic variability.

Since early diagnosis, followed with prompt initiation of ERT, may significantly improve its clinical benefits, universal screening has been advocated as a way to improve outcomes in Pompe patients [14]. For LOPD, delayed diagnosis is not unusual and has been reported to be made almost 10 years after the onset of symptoms [15]. Pilot newborn screening programs are in development or in progress in the US, and are well established in Taiwan using dried blood spots [16-18]. Although LOPD cases can be detected by newborn screening, undiagnosed children and adults will not benefit from ongoing development of these screening programs. Current methodologies to confirm the diagnosis of Pompe include mutation analysis by Sanger sequencing and enzyme testing in fibroblasts or leukocytes using fluorimetric methods, or more recently, on dried blood spot by tandem mass spectrometry $[4,19,20]$. All these methods are contingent on a strong clinical suspicion of Pompe disease and do not detect the presence of other muscle disorders. Given the rarity of Pompe disease and despite published diagnostic guidelines to educate clinicians, testing for Pompe disease is often overlooked [4]. The need exists for more comprehensive diagnostic tools targeting Pompe disease among other muscle disorders with overlapping clinical manifestations. The differential diagnosis of Pompe disease includes many genetic muscle disorders with limb-girdle weakness or rigid spine syndrome, which may be difficult to differentiate on a clinical basis alone [4]. However, next-generation sequencing (NGS) has the capability to test concurrently for all these muscle disorders.

NGS technologies make it possible to perform several millions of accurate sequence reactions in parallel on solid support, each producing a short sequence called a "read" [21]. Sequence enrichment methods are available to limit the analysis to the exons of selected genes of interest (gene panels). Pitfalls of sequence enrichment include low number of sequence reads in GC-rich regions or very low GC content, which would need to be sequenced by the conventional Sanger method to prevent false negatives [22, 23].

We developed a gene panel to simultaneously analyze genes associated with several muscle disorders with overlapping phenotypes in order to increase the diagnosis of LOPD in children and adults, of other disorders with non-specific muscle patterns and of patients with atypical presentations. We validated this gene panel using CEPH cell line NA12878 and samples from known Pompe patients and determined its clinical validity among a group of patients with undetermined muscle disorders. In parallel, we validated a method to determine acid alpha-glucosidase activity on dried blood spots (DBS) by tandem mass spectrometry, and correlated the enzyme activity data with results from the gene panel.

\section{Methods \\ Gene panel design}

We included genetic disorders that are part of the differential diagnosis of LOPD [4, 24]: muscular dystrophies with limb-girdle weakness pattern, rigid spine syndromes, scapuloperoneal syndromes, congenital myasthenic syndromes, congenital myopathies (nemaline, myofibrillar), congenital muscular dystrophies, metabolic myopathies (fatty acid oxidation disorders, glycogen storage disorders), and peroxisomal disorders. We excluded disorders for which the main molecular defect could not be detected reliably by NGS (repeat expansions and structural variants), such as fascioscapulohumeral dystrophy. Mitochondrial genes (mtDNA and nuclear) were excluded as well, owing to the large number of genes involved. The gene list was circulated among collaborators with special expertise in Pompe disease, medical and biochemical genetics, and neurogenetics. The final gene panel comprised 78 genes 
(Additional file 1: Table A). In order to design oligonucleotide probes for sequence enrichment, we delineated the genomic coordinates of exons of selected genes (all alternate transcripts) based on GRCh37/hg19 genome assembly and RefSeq gene definition (11/2013). Genomic coordinates were sent to Nimblegen Bioinformatics Production team (Madison, USA) to complete the design of the oligonucleotide probes, based on the exome enrichment kit V3. We allowed up to five perfect matches on the human genome for each probe to maximize the number of selected genomic regions covered, when necessary. In-solution hybridization oligonucleotide probe library was produced accordingly to SeqCapEZ ${ }^{\circ}$ technology (Roche/Nimblegen)

Determination of the analytical validity of the gene panel We analysed 20 Pompe patients and the NA12878 $\mathrm{CEPH}$ cell line to determine the sensitivity and specificity of the gene panel. The genome of NA12878 has been analyzed by multiple sequencing platforms and high quality confident genotypes are available to assess sensitivity and specificity (http://genomeinabottle.org) [25]. DNA was obtained from known Pompe patients, followed at the Division of Medical Genetics at Duke University Medical Center. All patients have been diagnosed on the basis of decreased acid alpha-glucosidase enzyme activity and had results from GAA Sanger sequencing available. Known mutations and polymorphisms were used for comparison with results from NGS (Additional file 1: Table B).

\section{Next-generation sequencing}

Sequencing of the gene panel by NGS was performed as follows: DNA from samples was fragmented to a mean size of $\sim 350 \mathrm{bp}$ by sonication (Covaris M220). Then, sequencing libraries were prepared with TruSeq ${ }^{\circ}$ library kit (Illumina) according to the manufacturer's protocol, except for the following modifications at the library amplification step by LM-PCR: in order to minimize amplification bias related to GC content, we substituted the provided polymerase by the KAPA HIFI HotStart polymerase (KAPA biosystems), and we used the following amplification conditions with initial denaturation for $45 \mathrm{sec}$ at $98{ }^{\circ} \mathrm{C}$, followed by seven cycles with $15 \mathrm{sec}$ at $98{ }^{\circ} \mathrm{C}, 30 \mathrm{sec}$ at $60{ }^{\circ} \mathrm{C}$ and $30 \mathrm{sec}$ at $72{ }^{\circ} \mathrm{C}$, ending with final extension step $1 \mathrm{~min}$ at $72{ }^{\circ} \mathrm{C}$. We then performed enrichment of exonic and flanking intronic sequences of selected genes in 12 samples in a multiplex reaction using our custom in-solution hybridization oligonucleotide probe library (SeqCapEZ ${ }^{\circ}$, Nimblegen). We followed the manufacturer's protocol, but decreased the number of post-capture amplification cycles to 13 to minimize amplification bias related to GC content. Enrichment efficiency was measured by quantitative PCR for one GC- rich locus (GAA exon 14, $66 \% \mathrm{GC}$ content) and 2 loci with average GC-content (TPM1 exon 1, 57 \% GC; $M Y B P C 3$ exon 6, 53 \% GC). Multiplexed samples were sequenced if they met a minimal acceptable enrichment factor of 800-1000X. Sequencing was done on a MiSeq ${ }^{\circ}$ sequencer (Illumina) using paired-end protocol (150 pb) and V2 chemistry. On average, 12.4 millions of pass filter reads were produced per sequencing run with $95.4 \%$ of reads having an average Phred score quality above Q30 (1 error in 1000 bases).

\section{Bioinformatics analysis}

We analyzed the sequencing data on a Linux-based bioinformatics pipeline developed by MUGQIC (https://bitbucket.org/mugqic/mugqic_pipelines). Briefly, 1) raw reads were trimmed using Trimmomatic (version 0.32) $[26], 2)$ sequence alignment was performed with Burrows-Wheeler Aligner (version 0.7.10) [27], 3) genetic variations (SNP and indels) were called with haplotypeCaller using the Genome Analysis Toolkit (version 3.2.2) [28, 29] with prior local realignment, base recalibration and removal of PCR duplicates using Picard (version 1.123, http://broadinstitute.github.io/picard/), 4) gene annotation was performed with SnpEff/SnpSift (version 3.6, including SIFT, Polyphen2, MutationTaster predictions) [30] with an additional in-house script to annotate variations present in ClinVar database [31], 5) a filtering process removed variations outside targeted sequences, with population frequency $>1 \%$ (dbSNP 138 and ExAC 0.3; http://exac.broadinstitute.org), genotype quality less than Q30 or present in 3/20 or more local controls sequenced on the same platform (therefore considered as artefacts). In order to identify single exon deletions in the GAA gene, we manually inspected the read coverage depth across $G A A$ for each patient compared to NA12878 cell line, using the Integrative Genomics Viewer (see Additional file 1: Figure A) [32]. Small deletions (less than 3 exons), remain challenging for current software [33-35]. Coverage depth was calculated using Browser Extensible Data (BED) Tools [36] and SAMtools [37] from the Galaxy web-based platform [38], as described in detail in the Additional file 1.

\section{Measurement of the acid alpha-glucosidase enzyme activity in dried blood spots (DBS) by tandem mass spectrometry}

The method for the acid alpha-glucosidase activity measurements in DBS was adapted from Dajnoki et al. [39] and is described in detail in the Additional file 1. The enzyme activity was analyzed in $3.2 \mathrm{~mm}$ diameter DBS discs. The acid alpha-glucosidase substrate ([7-benzoylaminoheptyl)-\{2-[4-(3,4,5-trihydroxy-6-hydroxymethyl-tetrahydr o-pyran-2-yloxy)-phenylcarbamoyl]-ethyl\}-carbamic acid t ert-butyl ester] and its internal standard (IS) [7-d5- 
benzoylamino-heptyl)-[2-(4-hydroxyphenylcarbamoyl)ethyl]-carbamic acid tertbutyl ester] were manufactured by Genzyme, A Sanofi Division (Framingham, MA) and distributed by the Centers for Disease Control and Prevention (CDC), Newborn Screening Branch, (Atlanta, GA). The product of the enzymatic reaction and its internal standard were analyzed by tandem mass spectrometry using a Quattro Micro (Waters Corp.) in the multiple reaction monitoring mode in positive electrospray ionization.

\section{Assessment of clinical utility of the gene panel}

We recruited pediatric and adult patients with undetermined muscle disorders referred to or already followed at specialized neuromuscular or genetic clinics in different provinces in Canada (Sherbrooke, Saguenay, Montreal in Quebec and Calgary, Alberta). Inclusion and exclusion criteria are shown in Fig. 1. Each participant provided written informed consent. The study was approved by the institutional ethics committee of the Université de Sherbrooke (project 12-208). A blood sample was drawn from each participant for DNA extraction (QIAamp DNA blood mini kit, Qiagen) and a DBS specimen was collected to measure acid alpha-glucosidase enzyme activity. For 24 patients, whole blood was collected in sodium heparinized tubes and enzyme testing

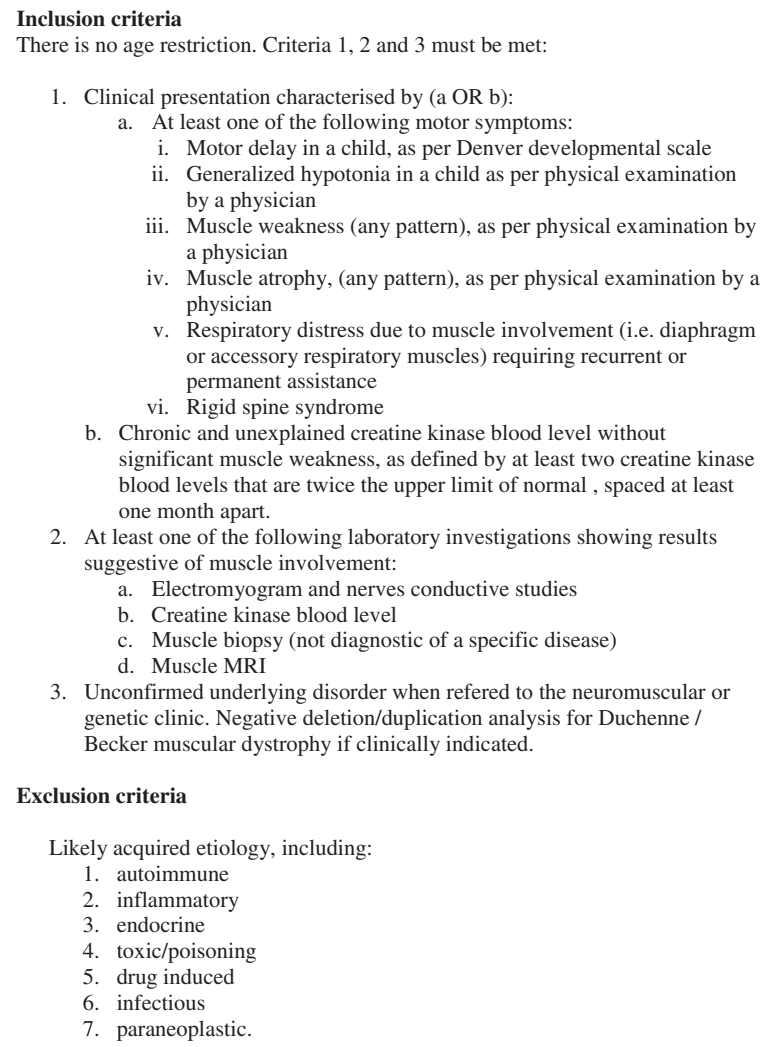

Exclusion criteria

Fig. 1 Inclusion and exclusion criteria was performed on leucocytes by previously described standard spectrophotometric assay [40].

NGS followed by bioinformatic analysis was then performed on the DNA sample as described above. Coverage depth of exons of GAA in all patients was manually reviewed for heterozygous exon deletions as described in 2.4 , owing to the relatively high frequency of whole exon 18 deletion. Similarly, in patients with a single causal variation in recessive disorders, we searched the relevant gene for heterozygous exon deletion. Suspected heterozygous exon deletions were confirmed by $\mathrm{qPCR}$ analysis or Sanger sequencing if breakpoints were known. In patients who did not have causal variations identified, 6 exons with consistently insufficient coverage $(<20 \mathrm{X}$; $S G C B$ exon 1, SEPN1 exon 1 and 3, PLEC exon 32, FKRP part of exon 4, PEX10 exon 1) were sequenced to exclude mutations by the Sanger method on a 3730XL DNA analyzer (Applied Biosystems) at McGill University and Genome Quebec Innovation Center. Putative causal variations were sequenced in parents when available and were classified accordingly to the ACMG recommendations [41].

\section{Results}

The gene panel comprises GAA along with 77 other genes causing muscle disorders that are considered in the differential diagnosis of LOPD $[4,24]$. The complete gene list is available in the Additional file 1 section (Table A). Before investigating the clinical utility of the gene panel, we sought to determine the analytical validity of our method across all targeted genes and more specifically for $G A A$, the gene responsible for Pompe disease. We sequenced the NA12878 CEPH cell line in two independent sequencing runs, among known Pompe patients and neuromuscular patients for a total of 12 samples per sequencing run.

\section{Analytical validity of the gene panel}

We determined the sensitivity and specificity across all selected genes by performing a comparison of observed genotypes with reference genotypes of the $\mathrm{CEPH}$ cell line NA12878. The genome of NA12878 has been analyzed by multiple sequencing platforms and high quality reliable genotypes are available to assess sensitivity and specificity (http://genomeinabottle.org) [25]. We observed a sensitivity of $100 \%$ (95 \% C.I.: 99-100 \%) using a set of 373 known variations (359 SNV and 14 indels) across all selected genes. Median coverage was 216X and only 6/1720 exons $(0.3 \%)$ did not show a coverage depth consistently above 20X, which would need Sanger sequencing to exclude variations. All GAA exons were successfully covered with $>20 \mathrm{X}$. In order to calculate the specificity, we restricted our analysis to variations located in exons and splice site junctions (+/- $5 \mathrm{bp})$, which 
are more relevant for disease causing variations. Deep intronic regions contain more frequently repetitive sequences that yield higher false positive rates. A total of 208 variations (204 SNV and 4 indels) were detected in exons and splice site junctions of selected genes. Among these, four variations ( 1 indel) were not found in the reference genotypes, which yielded a specificity of $98 \%$ (95 \% C.I.: 95-99 \%).

We analysed the sequencing data of 20 Pompe patients with known mutations and polymorphisms to determine more specifically the sensitivity of our method for variations located in the GAA gene. Our gene panel showed a $100 \%$ sensitivity (95 \% C.I.: $98-100 \%$ ) based on the analysis of 197 known single nucleotide variations and indels (36 SNV and 6 indels; Additional file 1: Table B). Median coverage of GAA for each Pompe patient sequenced ranged from $72 \mathrm{X}$ to $150 \mathrm{X}$. All GAA exons were successfully covered with $>20 X$. In addition, deletion of whole exon 18 was correctly detected by manual read depth inspection in 5/5 Pompe patients.

\section{Validation of DBS acid alpha-glucosidase activity by tandem mass spectrometry}

For the tandem mass spectrometry method validation, quality control (QC) DBS at four different enzyme levels of activity (from low QC1 to high QC4) were supplied by the CDC and used to measure the intra- and interday assay precision of the method (Table 1). Fifteen DBS from diagnosed Pompe patients were analyzed as positive quality controls and 49 DBS from healthy controls were analyzed to establish normal values for the GAA enzyme activity. The GAA activity was abnormal, with mean 0.51 (observed range nd-3.09) $\mu \mathrm{mol} / \mathrm{h} / \mathrm{L}$ for the 15 diagnosed Pompe patients and normal, with mean 8.57 (observed range 4.72-16.36) $\mu \mathrm{mol} / \mathrm{h} / \mathrm{L}$ for the 49 healthy controls. These results show that our method, which is scaled down from the current large-scale protocol [39]

Table 1 GAA enzyme activity intra- and interday assays using DBS from low to high quality controls (QCs)

\begin{tabular}{lllll}
\hline \multicolumn{5}{l}{ Intraday assays $(n=5)$} \\
QC1 & QC2 & QC3 & QC4 \\
Mean $(\mu \mathrm{mol} / \mathrm{h} / \mathrm{L})$ & 0.28 & 0.84 & 6.79 & 13.67 \\
Range $(\mu \mathrm{mol} / \mathrm{h} / \mathrm{L})$ & $0.20-0.49$ & $0.75-0.89$ & $6.20-7.64$ & $11.50-15.83$ \\
RSD\% & 41.42 & 6.44 & 8.70 & 12.79 \\
& Interday assays $(\mathrm{n}=5)$ & & \\
& QC1 & QC2 & QC3 & QC4 \\
Mean $(\mu \mathrm{mol} / \mathrm{h} / \mathrm{L})$ & 0.33 & 1.00 & 7.29 & 13.70 \\
Range $(\mu \mathrm{mol} / \mathrm{h} / \mathrm{L})$ & $(0.17-0.53)$ & $(0.69-1.44)$ & $(6.85-7.69)$ & $(12.08-15.09)$ \\
RSD\% & 38.75 & 27.17 & 4.22 & 9.37 \\
\hline
\end{tabular}

$R S D$ relative standard deviation and is thus less expansive, provides a similar high quality of results.

\section{Clinical utility of the gene panel}

We assessed the clinical utility of the gene panel in a cohort of pediatric and adult patients referred and followed at specialized neuromuscular and genetic clinics for an undetermined suspected muscle disease. A total of seven pediatric and 27 adult patients were recruited and sequenced. Median coverage for each patient ranged from $81 X$ to $361 X$, for a mean of $168 X$. Most patients presented with proximal muscle weakness or a more diffuse pattern with distal involvement (Table 2). At the time of recruitment $24 / 34$ patients $(71 \%)$ had undergone a muscle biopsy and 15/34 (44 \%) had at least one single gene test performed, but remained without a diagnosis.

We identified one Pompe patient harbouring 2 known pathogenic variations (P29), the c.-32-13T > G mutation, associated with LOPD, and the recurrent exon 18 deletion. In four other patients, we identified pathogenic variations supportive of an inherited muscle disorder (Table 3), for a diagnostic yield of $15 \%$. Likely pathogenic variations, variants of uncertain clinical significance or a combination of both were found in six patients, suggesting additional diagnoses. In three of these patients, revision of available muscle biopsy or additional immunohistochemistry supported the diagnosis (P22, P25, P27). In the three others, family history was in agreement with expected heritability, but samples were not available for segregation study. In total, a putative diagnosis was found in $11 / 34$ (32 \%) patients (Table 3). Most diagnoses showed various types of limbgirdle muscular dystrophies, although some had atypical presentations with respect to the causative gene (P25, P28, P29; see section 3.4). Acid alpha-glucosidase enzyme activity yielded normal results in all but one patient (P29), while abnormally low enzyme activity for P29 supported the diagnosis of Pompe disease made by molecular analysis (Table 3). One DBS sample was rejected on the basis of low control enzymes in addition to acid alpha-glucosidase, likely secondary to insufficient biological material (patient P27). Enzyme testing could not be repeated on a second sample, but a putative causal variation in the $V C P$ gene was found. Delay from initial symptoms to diagnosis ranged from 1 year in pediatric patients to more than 20 years in adults. In patients without diagnosis, we observed 0-5 heterozygous variants of uncertain significance altering the protein sequence of different recessive disorders.

\section{Atypical cases}

Patient P25 showed unusual late onset of symptoms for a patient with $N E B$ mutations. The patient had normal birth history and psychomotor development. Objective 
Table 2 Recruited patients with undermined muscle disease

\begin{tabular}{llll}
\hline Clinical presentation & Nbr of patients (pediatric patients) & Proportion of clinical presentations (\%) & Proportion of diagnoses (\%) \\
\hline Motor delay or generalized hypotonia & $4(4)$ & $4 / 34(11.8 \%)$ & $2 / 11(18 \%)$ \\
Limb-girdle muscle weakness & $17(1)$ & $17 / 34(50.0 \%)$ & $6 / 11(55 \%)$ \\
Proximal and distal limb muscle weakness & $4(2)$ & $4 / 34(11.8 \%)$ & $3 / 11(27 \%)$ \\
Other muscle weakness & $3(0)$ & $3 / 34(8.8 \%)$ & $0 / 11(0 \%)$ \\
Chronic and unexplained hyperCKemia & $6(0)$ & $6 / 34(17.6 \%)$ & $0 / 11(0 \%)$ \\
Total & $34(7)$ & $100 \%$ & $11 / 34(32 \%)$ \\
\hline
\end{tabular}

diffuse mild muscle weakness was only documented in adulthood. However, muscle weakness might have preceded adulthood since reduced body weight was reported in early teenage years with decreased tolerance for moderate intensity exercise. However, no further investigation was performed at that time, until adulthood. Muscle biopsy showed nemaline inclusions in a configuration supporting a diagnosis of CAP myopathy. Sequencing of TPM2, TPM3 and ACTA1 was negative. The patient remains fully ambulatory. Patient 28 showed an unusual severe and early onset of symptoms for a heterozygous carrier of a truncating mutation in $D M D$. She presented with limb girdle weakness before 10 years of age, high $\mathrm{CK}$ and limited long distance walking. There was no family history of affected males with muscular dystrophy, and she had a daughter who showed similar symptoms at 11 years. Muscle biopsy performed in the context of autosomal dominant limb-girdle dystrophy failed to support a specific diagnosis. Patient P29, who was diagnosed with Pompe disease, showed a peculiar phenotype, which likely contributed to delay in diagnosis. The patient is a female born prematurely at 32 weeks of gestational age. She showed motor and language delay, with walking at 3 years and first words around 2.5 years. Neuropsychological evaluation revealed a mild intellectual deficit. She received a diagnosis of cerebral palsy early in the course. She was otherwise known for obesity, hypertension and past history of seizures. Although she was reported to present long lasting gait disturbances, it was only at the age of 36 years that

Table 3 Putative causal variations in patients with undetermined neuromuscular diseases

\begin{tabular}{|c|c|c|c|c|c|c|c|}
\hline Patient & $\begin{array}{l}\text { Age } \\
\text { (years) }\end{array}$ & $\begin{array}{l}\text { Age of } \\
\text { onset (years) }\end{array}$ & Clinical presentation & Gene & $\begin{array}{l}\text { Variation } 1 \\
\text { (interpretation) }\end{array}$ & $\begin{array}{l}\text { Variation } 2 \\
\text { (interpretation) }\end{array}$ & Disorder inheritance \\
\hline P11 & 10 & 6 & $\begin{array}{l}\text { Proximal and distal limb } \\
\text { muscle weakness }\end{array}$ & COL6A1 & $\begin{array}{l}\text { C.1059+1 G>A } \\
\text { (Pathogenic) }\end{array}$ & - & Bethlem myopathy (AD) \\
\hline P13 & 11 & 0.3 & Motor delay & DNAJB6 & $\begin{array}{l}\text { c. } 525 \mathrm{C}>\text { G p.Phe175Leu } \\
\text { (VUS) }\end{array}$ & - & LGMD1E (AD) \\
\hline P17 & 21 & 11 & $\begin{array}{l}\text { Proximal and distal limb } \\
\text { muscle weakness }\end{array}$ & FKTN & $\begin{array}{l}\text { c.607C > T p.Arg203Ter } \\
\text { (Likely path.) }\end{array}$ & $\begin{array}{l}\text { c. } 1238 \mathrm{G}>\mathrm{T} \\
\text { p.Cys413Phe (VUS) }\end{array}$ & LGMD2M (AR) \\
\hline P20 & 35 & 25 & $\begin{array}{l}\text { Limb-girdle muscle } \\
\text { weakness }\end{array}$ & ANO5 & $\begin{array}{l}\text { c.1295C > G p.Ala432Gly } \\
\text { (Pathogenic) }\end{array}$ & $\begin{array}{l}\text { c.989dupT p.Leu } \\
\text { 330Phefs (Pathogenic) }\end{array}$ & LGMD2L (AR) \\
\hline P21 & 56 & N/A & $\begin{array}{l}\text { Limb-girdle muscle } \\
\text { weakness }\end{array}$ & COL6A3 & $\begin{array}{l}\text { c.5658G > A p.Arg1886Cys } \\
\text { (VUS) }\end{array}$ & - & Bethlem myopathy (AD) \\
\hline P22 & 46 & $<26$ & $\begin{array}{l}\text { Limb-girdle muscle } \\
\text { weakness }\end{array}$ & DYSF & $\begin{array}{l}\text { c. } 2448+2 T>G \\
\text { (Likely path.) }\end{array}$ & $\begin{array}{l}\text { c.3351_3352delAG } \\
\text { p.Thr1117Thrfs (Likely path.) }\end{array}$ & LGMD2B (AR) \\
\hline P25 & 48 & N/A & $\begin{array}{l}\text { Proximal and distal limb } \\
\text { muscle weakness }\end{array}$ & $N E B$ & $\begin{array}{l}\text { c.24339_24342del } \\
\text { p.Leu8113Leufs } \\
\text { (Likely path.) }\end{array}$ & $\begin{array}{l}\text { c. } 24113 \mathrm{C}>\text { A p.Ser8038Ter } \\
\text { (Likely path.) }\end{array}$ & Nemaline myopathy (AR) \\
\hline P27 & 60 & 57 & $\begin{array}{l}\text { Limb-girdle muscle } \\
\text { weakness }\end{array}$ & VCP & $\begin{array}{l}\text { C. } 1158 \mathrm{~T}>\text { C p.Lys } 386 \mathrm{Glu} \\
\text { (VUS) }\end{array}$ & - & $\begin{array}{l}\text { Inclusion body myopathy } \\
\text { (AD) }\end{array}$ \\
\hline P28 & 43 & $<10$ & $\begin{array}{l}\text { Limb-girdle muscle } \\
\text { weakness (female) }\end{array}$ & $D M D$ & $\begin{array}{l}\text { c.7683G > A (p.Trp2561Ter) } \\
\text { (Pathogenic) }\end{array}$ & - & $\begin{array}{l}\text { Duchenne muscular } \\
\text { dystrophy }(\mathrm{XL})\end{array}$ \\
\hline P29 & 48 & $<36$ & $\begin{array}{l}\text { Limb-girdle muscle } \\
\text { weakness }\end{array}$ & GAA & c.-32-13T> G (Pathogenic) & $\begin{array}{l}\text { Exon } 18 \text { deletion } \\
\text { (Pathogenic) }\end{array}$ & Pompe disease (AR) \\
\hline P30 & 1 & 0 & $\begin{array}{l}\text { Motor delay and } \\
\text { generalized hypotonia }\end{array}$ & POMT2 & $\begin{array}{l}\text { c.1997A > Gb p.Tyr666Cys } \\
\text { (Pathogenic) }\end{array}$ & $\begin{array}{l}\text { c.1997A > G b p.Tyr666Cys } \\
\text { (Pathogenic) }\end{array}$ & $\begin{array}{l}\text { Muscular dystrophy- } \\
\text { dystroglycanopathy (AR) }\end{array}$ \\
\hline
\end{tabular}

${ }^{a}$ de novo variation; ${ }^{b}$ Parental heterozygous carrier status confirmed; N/A Not available, VUS variant of uncertain significance. Variations were classified accordingly to the ACMG recommendations 
progression of the disease made her unable to climb stairs at home and she began to use a walker. Weakness progressed and she became wheelchair-bound at the age of 47 years. At 48 years old, respiratory insufficiency was noted and treated with non-invasive ventilation at night. A muscle biopsy was performed and showed glycogen accumulation, and the patient was referred to the genetics clinic for suspicion of Pompe disease. Diagnosis was established on the basis of the acid alpha-glucosidase activity and mutation analysis as described above. In short, the delay from initial symptoms to diagnosis was at least 12 years and possibly more, owing to the long lasting history of gait disturbances. Enzyme replacement therapy was initiated in the weeks following the diagnosis and response is currently being assessed.

\section{Discussion}

Our work highlights the high clinical utility of gene panels in patients with suspected muscle disorders and their potential to facilitate the diagnosis of patients showing non-specific muscle weakness or atypical phenotypes. This gene panel approach might further increase diagnosis of muscle conditions and reduce diagnostic delay. We propose that gene panels should be used as a first-tier test in patients with suspected muscle disorders of undetermined etiology. With decreasing sequencing costs and increasing availability of NGS-based tests, there are several advantages of performing gene panels early in the investigation of patients with muscle weakness.

Firstly, gene panels offer a higher clinical utility than any single disorder test by enabling screening for several diseases with overlapping phenotypes at the same time. This is especially useful in the context of patients with non-specific muscle patterns, such as children with motor delay or adults with limb-girdle patterns which are frequently encountered in neuromuscular and genetics clinics. There are more than 25 different types of limb-girdle muscular dystrophies, which often could not be distinguished clinically [42]. Moreover, muscle biopsy and immunostains are of very limited utility to target molecular tests in some instances, such as ANO5 (patient P25) [42]. In these latter cases, diagnosis could require several molecular single gene tests which can be prohibitive when considering the broader differential diagnosis of limb-girdle muscle weakness: Pompe disease, dystrophinopathies, Bethlem myopathy, myofibrillar myopathies, metabolic myopathies and others [42]. All these conditions would be readily diagnosed with a gene panel like the one we have developed. In the present study, the rate of diagnosis reached up to $32 \%$ of patients tested, with $50 \%$ presenting with limb-girdle weakness. Since our cohort is enriched for patients who have been followed for years in specialized clinics without diagnosis and $44 \%$ of patients had previous negative molecular tests results, one would expect a higher rate of diagnosis if the gene panel was performed as a first-tier test. Previous studies performing targeted next generation sequencing, similarly as a second tier test in patients with muscular dystrophies, reported diagnostic yields ranging from 16 to $65 \%$ [43-45]. Even if no treatment is available for the majority of these conditions, benefits of genetic diagnosis include more accurate prognostic information, genetic counselling, family screening and prenatal diagnosis in severe cases.

Secondly, use of gene panels in patients with muscle weakness could facilitate the diagnosis of atypical phenotypes, and reduce diagnostic delay. Delay in diagnosis varied from 1 year in pediatric patients to more than 20 years in adults included in the present study. Patients P25, P28, and P29 showed atypical or unusual characteristics that likely contributed to delayed diagnosis. P25 showed unusual late onset of symptoms for $N E B$ mutations and biopsy showed features supporting a diagnosis of CAP myopathy. Most cases of NEB mutations present in the neonatal period or within the first years of life, although some late-onset presentations have been described [46-48]. Moreover, mutations in NEB was not a known cause of CAP myopathy at the time of clinical evaluation and had only been reported recently in a single case [49]. Patient P28, harbouring a truncating mutation in $D M D$, presented unusual severe limb-girdle weakness of pediatric onset. In the two largest reported series of $D M D$ mutation carriers, the proportion of manifesting carriers varied from 5 to $22 \%$ and the pediatric cases remained rare $[50,51]$. However, in recent studies, female carriers with pediatric onset of muscle weakness are becoming increasingly recognized [52, 53]. In our case, absence of affected male and a similarly affected daughter on family history further contributed to confusion about inheritance, leading to an erroneous working diagnosis of autosomal limb girdle dystrophy. Finally, the peculiar disease course and spectrum of clinical manifestations of P29, possibly related in part to premature birth and complications, certainly contributed to delay in the recognition of Pompe disease by at least 12 years. This is not unusual as final diagnosis was reported to be made almost 10 years after the onset of symptoms in LOPD [15]. Although this is debatable, earlier accessibility to our gene panel at the age of 36 years while progression to limb-girdle weakness became significant could have led to a more rapid diagnosis for this patient, and possibly a different outcome at 48 years of age. While we agree that Pompe disease should be considered in all patients with limb-girdle weakness, in practice it is likely that screening through acid alpha-glucosidase activity will not necessarily be requested by every adult neurologist owing in part to the low frequency of LOPD. 
In our view, gene panels represent a more comprehensive first-tier diagnostic option in this type of scenario, and are more likely to be adopted by the medical community. Nevertheless, it remains to be determined whether broad adoption of gene panel as a first-tier test would result in significant reduced delay in the diagnosis of LOPD leading to an impact on treatment outcome. This question is timely as next generation sequencing becomes more widespread in al practice clinic and also considering the current populations of children and adult who will not benefit from ongoing implementation of newborn screening.

The pitfalls of using gene panels as first-tier analysis in the place of enzyme activity for identification of Pompe disease include the identification of variants of unknown significance (VUS), detection of a single heterozygous mutation, and limited performance of current bioinformatic tools to detect deletions and duplications from targeted NGS data [33-35, 41]. The VUS rates will greatly vary from gene to gene, but large collaborative efforts to share mutation data, such as ClinVar, are underway to minimise this limitation [31]. In Pompe disease, $19 \%$ of 84 GAA variants reported in ClinVar that were not classified as likely benign, are of uncertain clinical significance (June 2015). The Pompe disease mutation database (www.pompecenter.nl/, June 2015) lists 71 variations with unknown effect among 426 variations (17 $\%)$ that are not classified as likely benign [54]. Consequently, most patients present with two pathogenic alleles, but enzyme testing may be needed as reflex testing in those harbouring a VUS [55-58]. In the present study, we did not identify VUSs in GAA in our cohort of 34 patients, although we observed 0-5 VUS per patient across all genes analyzed. Pompe patients with a single heterozygous mutation identified are uncommon and represent $2-17 \%$ of patients with enzyme-based diagnosis from several case series [55-58]. Assessment of recurrent exon 18 deletion and other deletions in the GAA gene is critical to minimize this number. Currently, bioinformatic identification of deletions and duplications with targeted NGS-based data is of limited sensitivity, especially for less than three exons [33-35]. However, we managed to detect the recurrent exon 18 deletion from manual inspection of read coverage compared to a control. As for VUSs, reflex enzyme testing is necessary here to exclude that a GAA mutation was missed. Owing to these limitations, testing for acid alpha-glucosidase activity would appear the test of choice in the context of a strong clinical suspicion of Pompe disease.

The current state of NGS technology favors the use of gene panels over exome sequencing in the clinical setting, although this is likely to change in upcoming years. Beside the higher cost of exome sequencing, the main disadvantage is related to more incomplete coverage of exonic sequences $(\sim 5 \%)$ owing to generally lower average coverage compared to panels [59-61]. Raising the average coverage of exome sequencing to reach those of gene panels will only lead to further increase of its cost disadvantage. In addition, it has to be demonstrated that the diagnostic yield of exome sequencing is significantly superior to a well-designed clinical panel $[59,60]$. Variants detected in genes that are ambiguously or not yet related to the patient's phenotype are likely to be of limited clinical utility. Interestingly, a recent study using exome sequencing showed similar yield compare to our study with 22 of 74 patients $(30 \%)$ classified as muscular dystrophies and related disorders [62]. Another study, from the Emory Genetics Laboratory, reported that exome sequencing missed about $18 \%$ of causative pathogenic variants detected by their neuromuscular gene panel [60]. Obviously, exome sequencing raises additional issues including increased number of VUSs, incidental findings and higher laboratory infrastructure cost for clinical implementation.

\section{Conclusion}

Our work highlights the high clinical utility of gene panels in patients with muscle disorders and its potential to facilitate the diagnosis of patients showing nonspecific muscle weakness or atypical phenotypes. This could potentially lead to earlier diagnosis, if performed as a first-tier test. It remains to be determined if this would have a significant impact on treatment outcome for LOPD.

\section{Additional file}

Additional file 1: Supplemental information. (DOCX 157 kb)

\section{Abbreviations}

DBS: dried blood spot; ERT: enzyme replacement therapy; LOPD: late-onset Pompe disease; NGS: next generation sequencing; VUS: variant of unknown significance.

\section{Competing interests}

The authors declare that the study was supported by a research grant from Genzyme, a Sanofi company (grant \# GZ-2012-10897; PI: S. Lévesque and coPI: C. Auray-Blais), and that one of the co-authors (JK) is a Genzyme's employee.

\section{Authors' contributions}

SLévesque designed the study, participated to the gene panel design, the bioinformatic analysis, the interpretation of genetic variants, and drafted the manuscript. CAB participated in the design of the study and to the analysis of the results of the GAA enzyme assay, and helped to draft the manuscript. EG carried out the next generation sequencing and participated in the interpretation of genetic variants. MB performed GAA enzyme activity assay and participated to its analysis. LDN coordinated recruitment of patients in neuromuscular and genetics clinics, participated in the interpretation of genetic variants, and helped to draft the manuscript. PEJ developed the bioinformatic pipeline, participated to the bioinformatic analysis and helped to draft the manuscript. SC, SLarue, MFR, WAH, AN, JM, and VD participated in the recruitment of patients and summarized the clinical data. BM participated in the recruitment of patients and summarized the clinical data, 
and participated in the gene panel design. PJW participated in the gene panel design and critical review of the manuscript. JK participated in the critical review of the manuscript. SA coordinated recruitment the Pompe patients and acquisition of Sanger sequencing for these patients. PK participated in the study design, in the gene panel design and critical review of the manuscript. All authors read and approved the final manuscript.

\section{Acknowledgements}

We would like to thank the patients and their families for their participation in the study. The study was supported by a research grant from Genzyme, a Sanofi Company (GZ-2012-10897). Sanger sequencing was performed at McGill University and Genome Quebec Innovation Center. Bioinformatics analyses were performed on the supercomputer Mammouth Parallèle 2 at Université de Sherbrooke, managed by Calcul Québec and Compute Canada. The operation of this supercomputer is funded by the Canada Foundation for Innovation (CFI), Ministère de l'Économie, de l'Innovation et des Exportations du Québec (MEIE), RMGA and the Fonds de recherche du Québec - Nature et technologies (FRQ-NT). We are also grateful to Waters Corporation for their scientific and technical support in mass spectrometry.

\section{Author details}

'Department of Pediatrics, Division of Medical Genetics, Faculty of Medicine and Health Sciences, Université de Sherbrooke, and Centre Hospitalier Universitaire de Sherbrooke, 3001, 12th Avenue North, Sherbrooke, QC J1H $5 \mathrm{~N} 4$, Canada. ${ }^{2}$ Departments of Biology and Computer Science, Faculty of Sciences, Université de Sherbrooke, Sherbrooke, QC, Canada. ${ }^{3}$ Department of Neurology, Notre-Dame Hospital, Université de Montréal, Montreal, QC, Canada. ${ }^{4}$ Department of Neurology, Université de Sherbrooke, and Centre Hospitalier Universitaire de Sherbrooke, Sherbrooke, QC, Canada. ${ }^{5}$ Department of Pediatrics, Cumming School of Medicine, University of Calgary, and Alberta Children's Hospital, Calgary, AB, Canada. 'Department of Pediatrics, Division of Pediatric Neurology, Université de Sherbrooke, and Centre Hospitalier Universitaire de Sherbrooke, Sherbrooke, QC, Canada. ${ }^{7}$ Neuromuscular Clinic, Centre de réadaptation en déficience physique de Jonquière, Saguenay, QC, Canada. ${ }^{8}$ Genzyme Corporation, a Sanofi Company, Cambridge, MA, USA. ${ }^{9}$ Department of Pediatrics, Division of Medical Genetics, Duke University Medical Center, Durham, NC, USA.

Received: 18 October 2015 Accepted: 17 January 2016

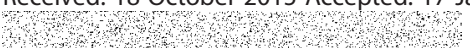

\section{References}

1. Hoefsloot LH, Hoogeveen-Westerveld M, Kroos MA, van Beeumen J, Reuser AJ, Oostra BA. Primary structure and processing of lysosomal alphaglucosidase; homology with the intestinal sucrase-isomaltase complex. EMBO J. 1988;7:1697-704

2. Hobson-Webb L, Proia AD, Thurberg BL, Banugaria S, Prater SN, Kishnani PS. Autopsy findings in late-onset Pompe disease: a case report and systematic review of the literature. Mol Genet Metab. 2012;106:462-9.

3. Kishnani PS, Beckemeyer AA, Mendelsohn NJ. The new era of Pompe disease: advances in the detection, understanding of the phenotypic spectrum, pathophysiology, and management. Am J Med Genet C: Semin Med Genet. 2012;160:1-7.

4. Kishnani PS, Steiner RD, Bali D, Berger K, Byrne BJ, Case LE, et al. Pompe disease diagnosis and management guideline. Genet Med. 2006;8:267-88.

5. Kishnani PS, Hwu WL, Mandel H, Nicolino M, Yong F, Corzo D, et al. A retrospective, multinational, multicenter study on the natural history of infantile-onset Pompe disease. J Pediatr. 2006:148:671-6.

6. van den Hout HM, Hop W, van Diggelen OP, Smeitink JA, Smit GP, Poll-The $B$, et al. The natural course of infantile Pompe's disease: 20 original cases compared with 133 cases from the literature. Pediatrics. 2003;112:332-40.

7. Schuller A, Wenninger S, Strigl-Pill N, Schoser B. Toward deconstructing the phenotype of late-onset Pompe disease. Am J Med Genet C: Semin Med Genet. 2012;160:80-8.

8. Gutiérrez-Rivas E, Bautista J, Vílchez JJ, Muelas N, Díaz-Manera J, Illa I, et al. Targeted screening for the detection of Pompe disease in patients with unclassified limb-girdle muscular dystrophy or asymptomatic hyperCKemia using dried blood: A Spanish cohort. Neuromuscul Disord. 2015;25:548-53.

9. Martiniuk F, Chen A, Mack A, Arvanitopoulos E, Chen Y, Rom WN, et al. Carrier frequency for glycogen storage disease type II in New York and estimates of affected individuals born with the disease. Am J Med Genet. 1998;79:69-72.

10. Ausems MG, Verbiest J, Hermans MP, Kroos MA, Beemer FA, Wokke JH, et al Frequency of glycogen storage disease type II in The Netherlands: implications for diagnosis and genetic counselling. Eur J Hum Genet. 1999; 7:713-6.

11. Hopkins PV, Campbell C, Klug T, Rogers S, Raburn-Miller J, Kiesling J. Lysosomal storage disorder screening implementation: findings from the first six months of full population pilot testing in Missouri. J Pediatr. 2015; 166:172-7.

12. Liao H-C, Chiang C-C, Niu D-M, Wang C-H, Kao S-M, Tsai F-J, et al. Detecting multiple lysosomal storage diseases by tandem mass spectrometry-a national newborn screening program in Taiwan. Clin Chim Acta. 2014:431:80-6.

13. Mechtler TP, Stary S, Metz TF, De Jesus VR, Greber-Platzer S, Pollak A, et al. Neonatal screening for lysosomal storage disorders: feasibility and incidence from a nationwide study in Austria. Lancet (London, England). 2012;379:335-41.

14. Kemper AR, Hwu WL, Lloyd-Puryear M, Kishnani PS. Newborn screening for Pompe disease: synthesis of the evidence and development of screening recommendations. Pediatrics. 2007;120:e1327-34.

15. Regnery C, Kornblum C, Hanisch F, Vielhaber S, Strigl-Pill N, Grunert B, et al. 36 months observational clinical study of 38 adult Pompe disease patients under alglucosidase alfa enzyme replacement therapy. J Inherit Metab Dis. 2012;35:837-45

16. Yang C-F, Liu H-C, Hsu T-R, Tsai F-C, Chiang S-F, Chiang C-C, et al. A large-scale nationwide newborn screening program for Pompe disease in Taiwan: towards effective diagnosis and treatment. Am J Med Genet A. 2014;164A:54-61.

17. Chien YH, Lee NC, Thurberg BL, Chiang SC, Zhang XK, Keutzer J, et al. Pompe disease in infants: improving the prognosis by newborn screening and early treatment. Pediatrics. 2009;124:e1116-25.

18. Burton BK. Newborn screening for Pompe disease: an update, 2011. Am J Med Genet C: Semin Med Genet. 2012;160:8-12.

19. Gelb MH, Turecek F, Scott CR, Chamoles NA. PMC2488386; Direct multiplex assay of enzymes in dried blood spots by tandem mass spectrometry for the newborn screening of lysosomal storage disorders. J Inherit Metab Dis. 2006;29:397-404.

20. Scott CR, Elliott S, Buroker N, Thomas LI, Keutzer J, Glass M, et al. Identification of infants at risk for developing Fabry, Pompe, or mucopolysaccharidosis-l from newborn blood spots by tandem mass spectrometry. J Pediatr. 2013;163:498-503.

21. Metzker ML. Sequencing technologies - the next generation. Nat Rev Genet. 2010;11:31-46.

22. Sulonen AM, Ellonen P, Almusa H, Lepistö M, Eldfors S, Hannula S, et al. Comparison of solution-based exome capture methods for next generation sequencing. Genome Biol. 2011;12:R94.

23. Samorodnitsky E, Datta J, Jewell BM, Hagopian R, Miya J, Wing MR, et al. Comparison of custom capture for targeted next-generation DNA sequencing. J Mol Diagn. 2015:17:64-75.

24. Howell RR, Byrne B, Darras BT, Kishnani P, Nicolino M, van der Ploeg A. Diagnostic challenges for Pompe disease: an under-recognized cause of floppy baby syndrome. Genet Med. 2006;8:289-96.

25. Zook JM, Chapman B, Wang J, Mittelman D, Hofmann O, Hide W, et al. Integrating human sequence data sets provides a resource of benchmark SNP and indel genotype calls. Nat Biotechnol. 2014;32:246-51.

26. Bolger AM, Lohse M, Usadel B. Trimmomatic: a flexible trimmer for Illumina sequence data. Bioinformatics. 2014:30:2114-20.

27. Li H, Durbin R. Fast and accurate short read alignment with BurrowsWheeler transform. Bioinformatics. 2009:25:1754-60.

28. McKenna A, Hanna M, Banks E, Sivachenko A, Cibulskis K, Kernytsky A, et al. The Genome Analysis Toolkit: a MapReduce framework for analyzing nextgeneration DNA sequencing data. Genome Res. 2010;20:1297-303.

29. Van der Auwera GA, Carneiro MO, Hartl C, Poplin R, Del Angel G, LevyMoonshine A, et al. From FastQ data to high confidence variant calls: the Genome Analysis Toolkit best practices pipeline. Curr Protoc Bioinformatics. 2013:11:11.10.1-11.10.33

30. Cingolani $P$, Platts $A$, Wang $L L$, Coon $M$, Nguyen $T$, Wang $L$, et al. A program for annotating and predicting the effects of single nucleotide polymorphisms, SnpEff: SNPs in the genome of Drosophila melanogaster strain w1118; iso-2; iso-3. Fly (Austin). 2012;6:80-92.

31. Landrum MJ, Lee JM, Riley GR, Jang W, Rubinstein WS, Church DM, et al. ClinVar: public archive of relationships among sequence variation and human phenotype. Nucleic Acids Res. 2014;42(Database issue):D980-5. 
32. Robinson JT, Thorvaldsdottir H, Winckler W, Guttman M, Lander ES, Getz G, et al. Integrative genomics viewer. Nat Biotechnol. 2011;24-26.

33. Retterer K, Scuffins J, Schmidt D, Lewis R, Pineda-Alvarez D, Stafford A, et al. Assessing copy number from exome sequencing and exome array CGH based on CNV spectrum in a large clinical cohort. Genet Med. 2014;17:623-9.

34. Samarakoon PS, Sorte HS, Kristiansen BE, Skodje T, Sheng Y, Tjonnfjord GE, et al. Identification of copy number variants from exome sequence data. BMC Genomics. 2014;15:661.

35. Tan R, Wang Y, Kleinstein SE, Liu Y, Zhu X, Guo H, et al. An evaluation of copy number variation detection tools from whole-exome sequencing data. Hum Mutat. 2014;35:899-907.

36. Quinlan AR, Hall IM. BEDTools: a flexible suite of utilities for comparing genomic features. Bioinformatics. 2010;26:841-2.

37. Li H, Handsaker B, Wysoker A, Fennell T, Ruan J, Homer N, et al. The Sequence Alignment/Map format and SAMtools. Bioinformatics. 2009;25: 2078-9.

38. Blankenberg D, Von Kuster G, Coraor N, Ananda G, Lazarus R, Mangan M, et al. Galaxy: a web-based genome analysis tool for experimentalists. Curr Protoc Mol Biol. 2010;Chapter 19:Unit 19.10.1-21.

39. Dajnoki A, Mühl A, Fekete G, Keutzer J, Orsini J, Dejesus V, et al. Newborn screening for Pompe disease by measuring acid alpha-glucosidase activity using tandem mass spectrometry. Clin Chem. 2008;54:1624-9.

40. Jack RM, Gordon C, Scott CR, Kishnani PS, Bali D. The use of acarbose inhibition in the measurement of acid alpha-glucosidase activity in blood lymphocytes for the diagnosis of Pompe disease. Genet Med. 2006;8:307-12.

41. Richards S, Aziz N, Bale S, Bick D, Das S, Gastier-Foster J, et al. Standards and guidelines for the interpretation of sequence variants: a joint consensus recommendation of the American College of Medical Genetics and Genomics and the Association for Molecular Pathology. Genet Med. 2015: 17:405-24.

42. Wicklund MP, Kissel JT. The limb-girdle muscular dystrophies. Neurol Clin. 2014:32:729-49. ix

43. Bartoli M, Desvignes J-P, Nicolas L, Martin K. Exome sequencing as a second-tier diagnostic approach for clinically suspected dysferlinopathy patients. Muscle Nerve. 2014;50:1007-10.

44. Seong M-W, Cho A, Park HW, Seo SH, Lim BC, Seol D, et al. Clinical applications of next-generation sequencing-based gene panel in patients with muscular dystrophy: Korean experience. Clin Genet. 2015.

45. Dai $Y$, Wei $X$, Zhao $Y$, Ren $H$, Lan Z, Yang Y, et al. A comprehensive genetic diagnosis of Chinese muscular dystrophy and congenital myopathy patients by targeted next-generation sequencing. Neuromuscul Disord. 2015;25:617-24.

46. Scoto M, Cullup T, Cirak S, Yau S, Manzur AY, Feng L, et al. Nebulin (NEB) mutations in a childhood onset distal myopathy with rods and cores uncovered by next generation sequencing. Eur J Hum Genet. 2013;21:1249-52

47. Romero NB, Lehtokari V-L, Quijano-Roy S, Monnier N, Claeys KG, Carlier RY, et al. Core-rod myopathy caused by mutations in the nebulin gene. Neurology. 2009;73:1159-61.

48. Wallgren-Pettersson C, Lehtokari V-L, Kalimo H, Paetau A, Nuutinen E, Hackman P, et al. Distal myopathy caused by homozygous missense mutations in the nebulin gene. Brain. 2007;130(Pt 6):1465-76.

49. Piteau SJ, Rossiter JP, Smith RG, MacKenzie JJ. Congenital myopathy with cap-like structures and nemaline rods: case report and literature review. Pediatr Neurol. 2014:51:192-7.

50. Hoogerwaard EM, van der Wouw PA, Wilde AA, Bakker E, Ippel PF, Oosterwijk JC, et al. Cardiac involvement in carriers of Duchenne and Becker muscular dystrophy. Neuromuscul Disord. 1999:9:347-51.

51. Sumita DR, Vainzof $M$, Campiotto $S$, Cerqueira AM, Canovas M, Otto PA, et al. Absence of correlation between skewed $X$ inactivation in blood and serum creatine-kinase levels in Duchenne/Becker female carriers. Am J Med Genet. 1998:80:356-61.

52. Papa R, Madia F, Bartolomeo D, Trucco F, Pedemonte M, Traverso M, et al. Genetic and Early Clinical Manifestations of Females Heterozygous for Duchenne/Becker Muscular Dystrophy. Pediatr Neurol. 2015.

53. Mercier S, Toutain A, Toussaint A, Raynaud M, de Barace C, Marcorelles $P$, et al. Genetic and clinical specificity of 26 symptomatic carriers for dystrophinopathies at pediatric age. Eur J Hum Genet. 2013;21:855-63.

54. Kroos M, Hoogeveen-Westerveld M, van der Ploeg A, Reuser AJJ. The genotype-phenotype correlation in Pompe disease. Am J Med Genet C: Semin Med Genet. 2012;160C:59-68.

55. Hermans MMP, van Leenen D, Kroos MA, Beesley CE, Van Der Ploeg AT, Sakuraba $\mathrm{H}$, et al. Twenty-two novel mutations in the lysosomal alpha- glucosidase gene (GAA) underscore the genotype-phenotype correlation in glycogen storage disease type II. Hum Mutat. 2004:23:47-56.

56. Montalvo AL, Bembi B, Donnarumma M, Filocamo M, Parenti G, Rossi M, et al. Mutation profile of the GAA gene in 40 Italian patients with late onset glycogen storage disease type II. Hum Mutat. 2006;27:999-1006.

57. Oba-Shinjo SM, da Silva R, Andrade FG, Palmer RE, Pomponio RJ, Ciociola KM, et al. Pompe disease in a Brazilian series: clinical and molecular analyses with identification of nine new mutations. J Neurol. 2009;256:1881-90.

58. Liu X, Wang Z, Jin W, Lv H, Zhang W, Que C, et al. Clinical and GAA gene mutation analysis in mainland Chinese patients with late-onset Pompe disease: identifying c.2238G > C as the most common mutation. BMC Med Genet. 2014;15:141.

59. Consugar MB, Navarro-Gomez D, Place EM, Bujakowska KM, Sousa ME Fonseca-Kelly ZD, et al. Panel-based genetic diagnostic testing for inherited eye diseases is highly accurate and reproducible, and more sensitive for variant detection, than exome sequencing. Genet Med. 2015;17:253-61.

60. Ankala A, da Silva C, Gualandi F, Ferlini A, Bean LJH, Collins C, et al. A comprehensive genomic approach for neuromuscular diseases gives a high diagnostic yield. Ann Neurol. 2015;77:206-14.

61. Sun Y, Ruivenkamp CAL, Hoffer MJV, Vrijenhoek T, Kriek M, van Asperen CJ, et al. Next-generation diagnostics: gene panel, exome, or whole genome? Hum Mutat. 2015:36:648-55.

62. Lee H, Deignan JL, Dorrani N, Strom SP, Kantarci S, Quintero-Rivera F, et al. Clinical exome sequencing for genetic identification of rare Mendelian disorders. JAMA. 2014;312:1880-7.

\section{Submit your next manuscript to BioMed Central and we will help you at every step:}

- We accept pre-submission inquiries

- Our selector tool helps you to find the most relevant journal

- We provide round the clock customer support

- Convenient online submission

- Thorough peer review

- Inclusion in PubMed and all major indexing services

- Maximum visibility for your research

Submit your manuscript at www.biomedcentral.com/submit
) Biomed Central 